Acta Crystallographica Section B

Structural

Science

ISSN 0108-7681

Gary S. Nichol, ${ }^{a}$ William

Clegg, $^{\text {a* }}$ Matthias J. Gutmann ${ }^{b}$ and Duncan M. Tooke ${ }^{a}$

${ }^{\mathrm{a}}$ School of Natural Sciences (Chemistry), Bedson Building, Newcastle University, Newcastle upon Tyne NE1 7RU, England, and ${ }^{\mathbf{b}}$ ISIS Neutron Facility, CCLRC Rutherford Appleton Laboratory, Chilton, Didcot, Oxfordshire OX11 0QX, England

Correspondence e-mail: w.clegg@ncl.ac.uk

\section{Stoichiometry-dependent structures: an X-ray and neutron single-crystal diffraction study of the effect of reaction stoichiometry on the crystalline products formed in the potassium-cyanurate system}

Reaction of cyanuric acid $\left(\mathrm{C}_{3} \mathrm{H}_{3} \mathrm{~N}_{3} \mathrm{O}_{3}\right.$; neutral form $\mathrm{CYH}_{3}$; anionic form $\mathrm{CYH}_{2}^{-}$; dianionic form $\mathrm{CYH}^{2-}$ ) with $\mathrm{K}_{2} \mathrm{CO}_{3}$ or $\mathrm{KOH}$ in aqueous solution gave three different crystalline products, according to the reaction stoichiometry used. The structures of two products were easily determined by singlecrystal X-ray diffraction: $\left[\mathrm{K}\left(\mathrm{CYH}_{2}\right)\left(\mathrm{H}_{2} \mathrm{O}\right)\right]$, (1), of which the crystal structure is already known [Marsh, R. E. et al. (2002). Acta Cryst. B58, 62-77], and $\left[\mathrm{K}_{2}(\mathrm{CYH})\right]$, (2), a highly symmetrical and dense structure. Further stoichiometric variation produced another new complex, (3), and reaction of $\mathrm{Rb}_{2} \mathrm{CO}_{3}$ with $\mathrm{CYH}_{3}$ yielded a further product, (4), which was found to be isostructural with (3). Determination of the structures of (3) and (4) by X-ray diffraction gave a result that was chemically unreasonable owing to a charge imbalance, with the asymmetric unit apparently containing 2- against $1.5+$ (partial charges as the result of crystallographic mirror symmetry). A single-crystal neutron diffraction analysis carried out on a fully deuterated sample of (3) revealed the presence of a supercell, with the $c$ axis doubled compared with the X-ray result. Subsequent refinement of the structure with this supercell showed that it is the result of just two D atoms breaking crystallographically imposed mirror symmetry, which is otherwise essentially observed by the rest of the structure. This minor deviation from pseudo-symmetry could not be identified by X-ray diffraction. Thus, single-crystal neutron diffraction data revealed that the true chemical formula of the structure of (3) [and presumably also of the isostructural (4) with $\mathrm{Rb}$ instead of $\mathrm{K}$ and $\mathrm{H}$ instead of $\mathrm{D}]$, is $\left[\mathrm{K}_{3}\left(\mathrm{C}_{3} \mathrm{D}_{2} \mathrm{~N}_{3} \mathrm{O}_{3}\right)_{3}\left(\mathrm{C}_{3} \mathrm{D}_{3} \mathrm{~N}_{3} \mathrm{O}_{3}\right)\left(\mathrm{D}_{2} \mathrm{O}\right)_{4}\right]$, the deuterated form of $\left[\mathrm{K}_{3}\left(\mathrm{CYH}_{2}\right)_{3}\left(\mathrm{CYH}_{3}\right)\left(\mathrm{H}_{2} \mathrm{O}\right)_{4}\right]$.

\section{Introduction}

Cyanuric acid $\left(\mathrm{C}_{3} \mathrm{H}_{3} \mathrm{~N}_{3} \mathrm{O}_{3}\right.$; neutral form $\mathrm{CYH}_{3}$; anionic form $\mathrm{CYH}_{2}^{-}$; dianionic form $\mathrm{CYH}^{2-}$ ) is a sturdy, robust and relatively unreactive small molecule which nevertheless has had a diverse role to play in chemistry, particular with regard to commercial or industrial use, for many years. It has featured in products ranging from flame retardants (Blount, 2000) and plant growth feed (Hudec et al., 1987) to a catalyst for $\mathrm{NO}_{x}$ removal from exhaust gases (Siebers \& Caton, 1990) and lavatory cleaning blocks (Barford et al., 1989). It is a mildly acidic compound with $\mathrm{p} K_{a}$ values of $6.85,10.91$ and $>12$ for the generation of the mono-, di- and trianionic forms, respectively (Aoki et al., 2000); whilst mono-deprotonation is easily achieved and double deprotonation can be achieved by careful control of the reaction equilibrium, triple deprotonation is much more uncommon and forms unstable complexes.
Received 31 March 2006 Accepted 29 June 2006
(C) 2006 International Union of Crystallography Printed in Great Britain - all rights reserved 
Despite the relative ease with which $\mathrm{CYH}_{3}$ can be singly deprotonated its use as an anionic ligand in coordination chemistry has so far been surprisingly restricted. With a few exceptions, reported coordination complexes have largely been confined to the first-row transition elements (Falvello $e t$ al., 1999, 1995, 1997; Server-Carrio et al., 1998; Slade et al., 1973) with the notable exception of work on silver complexes (Brunner et al., 2001; Munakata et al., 2001a,b; Rao et al., 2000). Of particular interest is work by Aoki et al. (2000) detailing the synthesis and structural characterization of macrocycle-stabilized zinc complexes of $\mathrm{CYH}_{3}$ in all three anionic forms.

By contrast to its coordination chemistry, the use of $\mathrm{CYH}_{3}$ in organic supramolecular chemistry has been investigated to a far deeper level. The molecule has $D_{3 h}$ symmetry and is a complementary hydrogen-bond partner for melamine, which also has $D_{3 h}$ symmetry, forming very strong hydrogen bonds. The formation of these bonds is predictable and reliable and has been well exploited in the formation of supramolecular compounds (Arduini et al., 2003; Berl et al., 2002; Felix et al., 2003; Mascal et al., 1999; Seto et al., 1993; Seto \& Whitesides, 1993; Whitesides et al., 1995; Zerkowski et al., 1994). Onedimensional and two-dimensional motifs predominate throughout.

We became interested in the coordination chemistry of $\mathrm{CYH}_{3}$ as part of our work on $s$-block metal complexes of pyridones, barbiturates and related ligands (Nichol \& Clegg, $2006 a, b)$. Whilst the composition of coordination complexes of all the alkaline-earth metals, and most of the alkali metals, is independent of the reaction stoichiometry used, we found that the potassium and caesium reaction systems were sensitive to the relative amounts of acid and base used. In particular, three different potassium cyanurate complexes can by obtained by simple variation of the amount of base used in the reaction. Whilst two of these complexes are straightforward with metalligand ratios of 1:1 $\left\{\left[\mathrm{K}\left(\mathrm{CYH}_{2}\right)\left(\mathrm{H}_{2} \mathrm{O}\right)\right]_{\infty}\right.$, compound (1) $\}$ and $2: 1\left\{\left[\mathrm{~K}_{2}(\mathrm{CYH})\right]_{\infty}\right.$, compound (2)\}, the initial formulation of a third complex, $\left[\mathrm{K}_{3}\left(\mathrm{CYD}_{2}\right)_{3}\left(\mathrm{CYD}_{3}\right)\left(\mathrm{D}_{2} \mathrm{O}\right)_{4}\right]_{\infty}$, (3), exhibited charge balance problems as the number of potassium cations did not equal the number of cyanurate anions in the asymmetric unit. The equivalent rubidium analogue, $\left[\mathrm{Rb}_{3}\left(\mathrm{CYH}_{2}\right)_{3^{-}}\right.$ $\left.\left(\mathrm{CYH}_{3}\right)\left(\mathrm{H}_{2} \mathrm{O}\right)_{4}\right]_{\infty}$, (4), was found to be isostructural with (3).

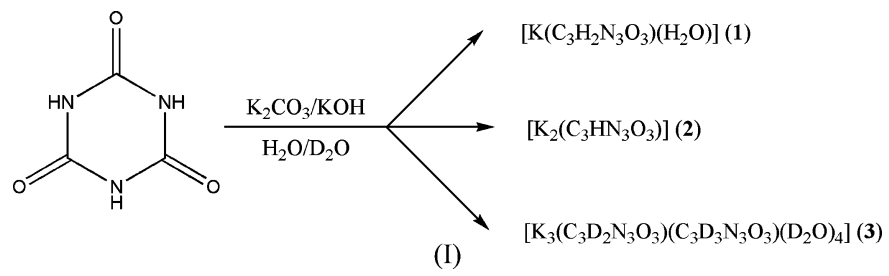

A single-crystal neutron diffraction data set was collected on a fully deuterated form of (3) in order to study the H-atom behaviour and hence to try to solve the charge balance problem. Crystals of (4) could not be grown large enough to permit neutron diffraction.

\section{Experimental}

\subsection{Synthesis}

2.1.1. Compound (1). $\mathrm{CYH}_{3}(0.132 \mathrm{~g}, 1 \mathrm{mmol}, 1$ equivalent) was dissolved in $30 \mathrm{ml}$ of distilled water, with heating and stirring. Solid $\mathrm{K}_{2} \mathrm{CO}_{3}(0.142 \mathrm{~g}, 1 \mathrm{mmol}, 2$ equivalents) was added to the reaction solution, resulting in instant effervescence. The solution was boiled until $c a 15 \mathrm{ml}$ remained, when the hot solution was transferred to a fresh sample vial, sealed and allowed to stand at room temperature. Large colourless crystals of (1) grew over a period of 2-3 d (0.076 g, 40\%). CHN analysis found: C 19.59, H 1.92, N 22.18\%; calc.: C 19.46, H 2.18, N 22.69\%.

2.1.2. Compound (2). $\mathrm{CYH}_{3}(0.134 \mathrm{~g}, 1 \mathrm{mmol}, 1$ equivalent) was dissolved in $30 \mathrm{ml}$ of water along with $\mathrm{KOH}(0.27 \mathrm{~g}$, $4.8 \mathrm{mmol}, 4.8$ equivalents). The reaction mixture was boiled until everything had dissolved. Slow evaporation of a small portion of the solution on a watchglass at room temperature yielded colourless crystals of (2). The amount of product obtained was too small to permit calculation of the yield or $\mathrm{CHN}$ analysis.

2.1.3. Compound (3). Under an atmosphere of dry nitrogen, $\mathrm{CYH}_{3}(0.134 \mathrm{~g}, 1 \mathrm{mmol}, 1$ equivalent) was dissolved in $30 \mathrm{ml}$ of deuterated water, with heating. Solid $\mathrm{K}_{2} \mathrm{CO}_{3}$ ( $0.071 \mathrm{~g}, 0.5 \mathrm{mmol}, 0.5$ equivalents) was added; the solution was boiled until all the solid reagents had dissolved and was then allowed to stand, undisturbed, at room temperature. Very large colourless block crystals of (3) formed over a period of around 1 week $(0.059 \mathrm{~g}, 17 \%)$. CDN analysis found: C 19.91, D 4.51, N 22.88\%; calc.: C 20.02, D 4.74, N 23.36\%.

2.1.4. Compound (4). $\mathrm{Rb}_{2} \mathrm{CO}_{3}(0.309 \mathrm{~g}, 1.3 \mathrm{mmol}, 1$ equivalent) and $\mathrm{CYH}_{3}(0.356 \mathrm{~g}, 2.75 \mathrm{mmol}, 2.1$ equivalent $)$ were dissolved in $40 \mathrm{ml}$ of boiling water. After $5 \mathrm{~min}$ of boiling the heat was removed and the flask sealed. A crop of large colourless crystals of (4) grew over a period of $2 \mathrm{~d}(0.111 \mathrm{~g}$, $10.16 \%)$. CHN analysis found: C 17.25, H 1.91, N 20.40\%; calc.: C 17.12, H 2.03, N 19.97\%.

\subsection{Crystallography}

2.2.1. Single-crystal X-ray diffraction. Crystallographic experimental parameters for all data collections are summarized in Table 1. ${ }^{\mathbf{1}}$ Tables $2-5$ give details of selected geometric and hydrogen-bonding parameters. Details of the singlecrystal neutron data collection are given in the following paragraph. For the X-ray data sets, data collection and reduction was by COLLECT (Nonius, 1999) and EvalCCD (Duisenberg et al., 2003) for (1), or SMART and SAINT (Bruker, 2001) for (2)-(4). For all four structures semiempirical absorption correction from symmetry-equivalent and repeated reflections was by SADABS (Sheldrick, 2003); structure solution (direct methods) and refinement was by SHELXTL (Sheldrick, 2001), using all unique $F^{2}$ values.

\footnotetext{
${ }^{1}$ Supplementary data for this paper are available from the IUCr electronic archives (Reference: BS5033). Services for accessing these data are described at the back of the journal.
} 
Table 1

Summary of crystallographic experimental parameters for all data collections.

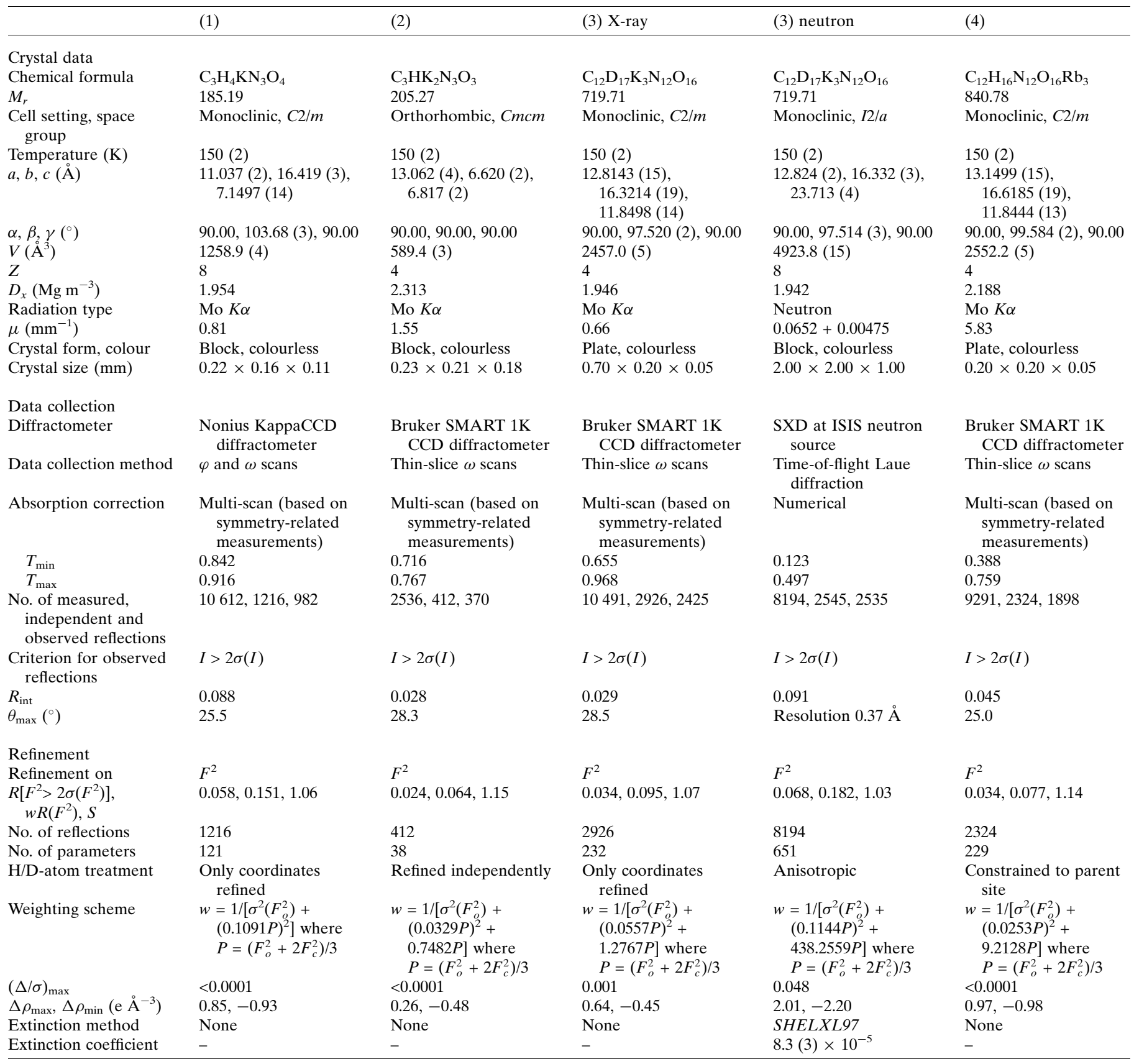

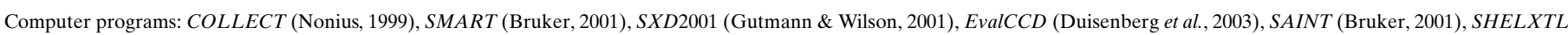
(Sheldrick, 2001) and local programs.

DIAMOND3 (Brandenburg \& Putz, 2004) and WinGX (Farrugia, 1999) were used to produce the molecular graphics.

2.2.2. Single-crystal neutron diffraction. Very large deuterated crystals (by normal X-ray diffraction standards) of compound (3) were prepared for the collection of a singlecrystal neutron diffraction data set on instrument SXD at the ISIS spallation neutron source, Rutherford Appleton Laboratories, Oxfordshire, UK (http://www.isis.rl.ac.uk/ crystallography/sxd/). SXD uses the time-of-flight Laue tech- nique to obtain reflections from large amounts of reciprocal space in a single measurement with a stationary crystal (Wilson, 2005; Keen et al., 2006). Data were collected from eight crystal orientations to a resolution of $0.37 \AA$, each experiment taking around $10 \mathrm{~h}$, giving a total data collection time of just over $3 \mathrm{~d}$.

The program $S X D$-2001 (Gutmann \& Wilson, 2001) was used to collect and process the neutron diffraction data. The structure was determined by using trial structures determined 
Table 2

Selected bond lengths $(\AA)$ for (1).

\begin{tabular}{llll}
\hline $\mathrm{K} 1-\mathrm{O} 1$ & $2.780(2)$ & $\mathrm{K} 1-\mathrm{O} 4^{\mathrm{ii}}$ & $2.726(18)$ \\
$\mathrm{K} 1-\mathrm{O} 5$ & $2.855(4)$ & $\mathrm{K} 1-\mathrm{O} 6$ & $2.696(4)$ \\
$\mathrm{K} 1-\mathrm{O}^{\mathrm{i}}$ & $3.079(4)$ & $\mathrm{K} 2-\mathrm{O} 3$ & $2.932(2)$ \\
$\mathrm{K} 2-\mathrm{O} 5$ & $2.738(3)$ & $\mathrm{K} 2-\mathrm{O} 5^{\mathrm{iii}}$ & $2.979(4)$ \\
$\mathrm{K} 2-\mathrm{O} 6$ & $2.859(4)$ & $\mathrm{K} 2-\mathrm{N} 2^{\mathrm{iv}}$ & $3.014(2)$ \\
$\mathrm{K} 2-\mathrm{N} 3$ & $3.010(3)$ & $\mathrm{O} 1-\mathrm{C} 1$ & $1.218(5)$ \\
$\mathrm{O} 2-\mathrm{C} 2$ & $1.258(4)$ & $\mathrm{O} 3-\mathrm{C} 3$ & $1.250(3)$ \\
$\mathrm{O} 4-\mathrm{C} 4$ & $1.228(5)$ & & \\
\hline
\end{tabular}

Symmetry codes: (i) $-x,-y,-z$; (ii) $-x+\frac{1}{2},-y+\frac{1}{2},-z+1$; (iii) $-x+1,-y,-z+1$; (iv) $x+\frac{1}{2}, y-\frac{1}{2}, z$.

Table 3

Selected bond lengths $(\AA)$ in (2).

\begin{tabular}{llll}
\hline $\mathrm{K}-\mathrm{O} 1$ & $2.7688(13)$ & $\mathrm{K}-\mathrm{O} 1^{\mathrm{i}}$ & $2.8773(14)$ \\
$\mathrm{K}-\mathrm{N} 2^{\mathrm{ii}}$ & $3.0390(15)$ & $\mathrm{K}-\mathrm{O} 2^{\mathrm{iii}}$ & $2.9058(8)$ \\
$\mathrm{O} 1-\mathrm{C} 1$ & $1.263(2)$ & $\mathrm{O} 2-\mathrm{C} 2$ & $1.278(4)$ \\
\hline
\end{tabular}

Symmetry codes: (i) $-x+\frac{1}{2},-y+\frac{3}{2},-z+1$; (ii) $-x+\frac{1}{2}, y+\frac{1}{2},-z+\frac{1}{2}$; (iii) $-x+\frac{1}{2},-y+\frac{1}{2},-z+1$.

Table 4

Selected bond lengths $(\AA)$ in the neutron-determined structure of (3).

\begin{tabular}{|c|c|c|c|c|c|}
\hline -O1 & 965 (15) & $\mathrm{K} 1-$ & $2.91(2)$ & $\mathrm{O} 1-\mathrm{C} 1$ & $1.240(9)$ \\
\hline & & $\mathrm{K} 1$ & $975(13$ & & \\
\hline $9^{\mathrm{ii}}$ & $2.863(16)$ & 2iii & & & \\
\hline 1 & & & & & \\
\hline & 2.751 & & & & 14) \\
\hline & & & & & \\
\hline & & & & & \\
\hline S- & 2 & K3- & & O8 & .21 \\
\hline $\mathrm{K} 3-\mathrm{O} 7$ & 2.833 & $\mathrm{~K} 3-\mathrm{O} 13$ & 2.707 (16) & $\mathrm{O} 9-\mathrm{C} 9$ & $1.230(11)$ \\
\hline D10-C10 & $1.278(12)$ & $\mathrm{O} 11-\mathrm{C} 11$ & $1.209(9)$ & $\mathrm{O} 12-\mathrm{C} 12$ & $1.255(12)$ \\
\hline
\end{tabular}

Symmetry codes: (i) $-x+\frac{1}{2},-y+\frac{3}{2},-z+\frac{1}{2}$; (ii) $x-\frac{1}{2},-y+2, z$; (iii) $-x+\frac{1}{2}, y,-z+1$; (iv) $-x+1,-y+2,-z+1$; (v) $-x+1,-y+1,-z+1$; (vi) $-x+1, y-\frac{1}{2},-z+\frac{1}{2}$.

Table 5

Hydrogen-bonding geometry $\left(\AA,^{\circ}\right)$ in the neutron-determined structure of (3).

\begin{tabular}{lllll}
\hline$D-\mathrm{D} \cdots A$ & $D-\mathrm{D}$ & $D \cdots A$ & $D \cdots A$ & $D-\mathrm{D} \cdots A$ \\
\hline $\mathrm{N} 1-\mathrm{D} 1 \cdots \mathrm{O} 9^{\mathrm{ii}}$ & $1.017(11)$ & $1.796(11)$ & $2.809(10)$ & $174(1)$ \\
$\mathrm{N} 3-\mathrm{D} 3 \cdots \mathrm{O} 10^{\mathrm{i}}$ & $1.054(12)$ & $1.701(13)$ & $2.734(12)$ & $165(2)$ \\
$\mathrm{N} 4-\mathrm{D} 4 \cdots 8^{\text {iv }}$ & $1.027(11)$ & $1.787(11)$ & $2.807(10)$ & $171(2)$ \\
$\mathrm{N} 5-\mathrm{D} 5 \cdots \mathrm{O} 16^{\mathrm{vii}}$ & $1.059(7)$ & $1.654(11)$ & $2.690(12)$ & $165(1)$ \\
$\mathrm{N} 6-\mathrm{D} 6 \cdots \mathrm{O} 12^{\text {viii }}$ & $1.060(10)$ & $1.681(11)$ & $2.738(11)$ & $175(1)$ \\
$\mathrm{N} 7-\mathrm{D} 7 \cdots \mathrm{O} 5^{\mathrm{iv}}$ & $1.043(12)$ & $1.708(12)$ & $2.746(12)$ & $173(1)$ \\
$\mathrm{N} 9-\mathrm{D} 9 \cdots \mathrm{O} 2^{\mathrm{vii}}$ & $1.034(11)$ & $1.736(12)$ & $2.763(11)$ & $172(1)$ \\
$\mathrm{N} 10-\mathrm{D} 10 \cdots \mathrm{O} 3^{\mathrm{i}}$ & $1.022(10)$ & $1.804(11)$ & $2.825(10)$ & $178(1)$ \\
$\mathrm{N} 11-\mathrm{D} 11 \cdots \mathrm{O} 6^{\mathrm{ix}}$ & $1.022(11)$ & $1.821(13)$ & $2.828(11)$ & $168(1)$ \\
$\mathrm{O} 13-\mathrm{D} 13 A \cdots \mathrm{N} 8^{\mathrm{vii}}$ & $0.968(12)$ & $1.866(12)$ & $2.830(12)$ & $174(1)$ \\
$\mathrm{O} 14-\mathrm{D} 14 A \cdots \mathrm{O} 2^{\mathrm{vii}}$ & $0.964(12)$ & $1.838(12)$ & $2.756(13)$ & $158(1)$ \\
$\mathrm{O} 14-\mathrm{D} 14 B \cdots \mathrm{O} 6^{\mathrm{vi}}$ & $0.959(11)$ & $1.866(12)$ & $2.768(13)$ & $156(1)$ \\
$\mathrm{O} 15-\mathrm{D} 15 A \cdots \mathrm{N} 12^{\mathrm{iii}}$ & $0.945(11)$ & $2.123(12)$ & $3.042(12)$ & $164(1)$ \\
$\mathrm{O} 15-\mathrm{D} 15 B \cdots \mathrm{N} 8^{\mathrm{ii}}$ & $0.946(12)$ & $2.190(15)$ & $3.098(11)$ & $160(1)$ \\
$\mathrm{O} 16-\mathrm{D} 16 A \cdots \mathrm{N} 2^{\mathrm{x}}$ & $0.964(10)$ & $1.771(8)$ & $2.733(12)$ & $175(1)$ \\
$\mathrm{O} 16-\mathrm{D} 16 A \cdots \mathrm{O} 3^{\mathrm{x}}$ & $0.964(10)$ & $2.705(11)$ & $3.293(13)$ & $120(1)$ \\
$\mathrm{O} 16-\mathrm{D} 16 B \cdots \mathrm{O} 13^{\mathrm{xi}}$ & $0.969(6)$ & $1.895(7)$ & $2.864(6)$ & $178(1)$
\end{tabular}

Symmetry codes: (i) $-x+\frac{1}{2},-y+\frac{3}{2},-z+\frac{1}{2}$; (ii) $x-\frac{1}{2},-y+2, z$; (iii) $-x+\frac{1}{2}, y,-z+1$; (iv) $-x+1,-y+2,-z+1$; (vi) $-x+1, y-\frac{1}{2},-z+\frac{1}{2}$; (vii) $x+\frac{1}{2},-y+2, z$; (viii) $x,-y+\frac{3}{2}, z-\frac{1}{2}$; (ix) $x,-y+\frac{3}{2}, z+\frac{1}{2}$; (x) $-x, y-\frac{1}{2},-z+\frac{1}{2}$; (xi) $x-1, y, z$. by X-ray analysis as a starting point and the remaining atoms located by carrying out successive Fourier and least-squares refinements with SHELXTL.

Carrying out the reaction using $\mathrm{D}_{2} \mathrm{O}$ as the solvent allows for deuterium-hydrogen exchange and incorporation of $\mathrm{D}_{2} \mathrm{O}$ in the structure. Deuterated samples have three important advantages over standard samples. Firstly, deuterium scatters neutrons over twice as strongly as hydrogen, giving an improvement in the intensity of the diffracted neutron beams. Secondly, hydrogen is one of the few nuclei which scatters neutrons out-of-phase, giving holes rather than peaks in a difference map. This property allows for easy checking that full deuteration has taken place, and makes difference map analysis more straightforward. Finally, hydrogen contributes significantly to incoherent and background scattering; using deuterium significantly reduces this problem.

\section{Results and discussion}

\subsection{Compound (1)}

As noted in the Experimental section this compound was synthesized using equimolar amounts of $\mathrm{K}_{2} \mathrm{CO}_{3}$ and $\mathrm{CYH}_{3}$. Thus, the $\mathrm{K}: \mathrm{CYH}_{3}$ ratio was $2: 1$. The crystal structure of this compound was first reported by Sysoeva et al. (1990) in space group $C m$, subsequently corrected to $C 2 / m$ by Marsh et al. (2002). We present here a low-temperature redetermination, for the purpose of comparison with the other compounds. The compound does indeed crystallize in space group $C 2 / m$ and shows no structural effect as a result of the cooling, other than a slight reduction in unit-cell volume, consistent with the effect of reduced temperature. The structure is shown in Fig. 1. There are two crystallographically independent $\mathrm{K}^{+}$cations and two crystallographically independent $\mathrm{CYH}_{2}^{-}$anions in the asymmetric unit, along with two molecules of water. Both cations and both water molecules are located on crystallographic mirror planes, and both anions are located on twofold rotation axes, so there are few unique atoms in this highly symmetrical structure. The two independent potassium cations have rather different coordination environments. Atom $\mathrm{K} 1$ is coordinated exclusively by $\mathrm{O}$ atoms from the carbonyl groups of both anions, and also by both water molecules. By contrast $\mathrm{K} 2$ is coordinated by an even combination of $\mathrm{N}$ and $\mathrm{O}$ atoms (four each). Atoms $\mathrm{K} 1$ and $\mathrm{K} 2$ are bridged by both water molecules, whilst $\mathrm{K} 1$ is bridged to its symmetry equivalents via carbonyl $\mathrm{O}$ atoms only and $\mathrm{K} 2$ is bridged to its symmetry equivalents via $\mathrm{N}$ atoms only. Both $\mathrm{K} 1$ and $\mathrm{K} 2$ are related to their symmetry equivalents by twofold rotation axes, the same axes which also pass through the $\mathrm{CYH}_{2}^{-}$anions. $\mathrm{K}-\mathrm{O}$ and $\mathrm{K}-\mathrm{N}$ bond lengths are unexceptional, as is the geometry of the $\mathrm{CYH}_{2}^{-}$anions. Table 2 gives selected geometrical parameters for compound (1).

Alongside this extensive coordination is a degree of predictable hydrogen bonding. The $R_{2}^{2}(8)$ motif (Bernstein et al., 1995) linking the $\mathrm{CYH}_{2}{ }^{-}$anions together via $\mathrm{N}-\mathrm{H} \cdots \mathrm{O}$ interactions is one of the most regular and persistent motifs in cyanuric structural chemistry (Falvello et al., 1997), so its 
appearance here, linking the anions into a tape, is unsurprising.

\subsection{Compound (2)}

As $\mathrm{CYH}_{3}$ can be potentially deprotonated at all three $\mathrm{NH}$ sites we experimented with the reaction conditions to see if we could doubly deprotonate the acid and observe the effect on the coordination chemistry. The instability of $\mathrm{CY}^{3-}$ complexes has already been mentioned so we considered that a $\left[\mathrm{K}_{3}(\mathrm{CY})\right]$ complex would be difficult or impossible to synthesize. The relatively high $\mathrm{p} K_{a}$ of the second deprotonation meant that hydroxide was preferable to carbonate as base. Double deprotonation and the formation of $\left[\mathrm{K}_{2}(\mathrm{CYH}) \cdot x \mathrm{H}_{2} \mathrm{O}\right]$ was achieved using approximately 5:1 $\mathrm{KOH}: \mathrm{CYH}$ in aqueous solution. Somewhat surprisingly, there is no water present in this compound and the structure is highly symmetrical, crystallizing in the orthorhombic space group $\mathrm{Cmcm}$ with only seven unique atoms in the asymmetric unit (Fig. 2).

Removal of the second proton means that the $R_{2}^{2}(8)$ motif is not formed and, as a result, this is one of only a handful of cyanuric structures not to feature this hydrogen-bonding motif. Instead there is a lone $\mathrm{N}-\mathrm{H} \cdots \mathrm{O}$ interaction forming a C6 motif which, because of the crystallographic symmetry, links the anions into linear chains. As hydrogen bonding is of little importance now, the structure is held together by a very dense network of coordination bonds. The calculated crystal density is $2.313 \mathrm{Mg} \mathrm{m}^{-3}$ and there are only 30 other compounds which contain potassium as the only metal in the Cambridge Structural Database (version 5.27 with January 2006 update; Allen, 2002) with a higher density. Atom O1 links four potassium centres and $\mathrm{N} 2$ bridges across two potassium centres, whilst atom $\mathrm{O} 2$, as the hydrogen-bond acceptor, does

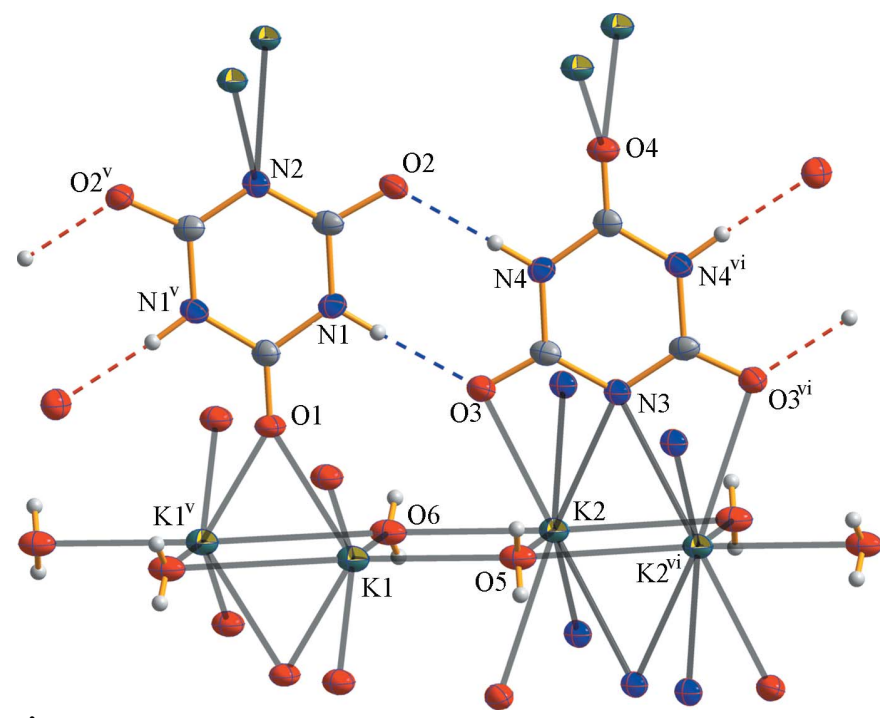

Figure 1

A partial packing diagram of (1). Displacement ellipsoids are drawn at the $50 \%$ probability level, and dashed lines indicate hydrogen bonding [symmetry codes (twofold rotation): (v) $-x, y,-z$; (vi) $-x+1, y,-z+1$ ]. In all graphical representations of structures in the on-line version of the journal, bonds within ligands are orange, and bonds to metals are semitransparent grey. not coordinate to the metal at all. The unique potassium centre is thus six-coordinate and its geometry can best be described as distorted pentagonal bipyramidal with one of the equatorial points removed. As with (1), the bond lengths and angles in this structure are unexceptional; selected bond lengths are given in Table 3.

A $c$-axis projection of the crystal packing (Fig. 3) shows quite neatly both the dense coordination bonding and its symmetrical nature in this structure. The $\mathrm{CYH}^{2-}$ rings are stacked along the $c$ axis with a lateral displacement between adjacent rings of approximately $1 / 3$ of a ring along the $b$ axis. The stacking distance between the rings is approximately $3.4 \AA$; this distance and the ring displacement are good indicators of ring-stacking stabilization. However, given the extent of metal-ligand coordination in this structure, it is unlikely that the ring stacking is a significant directing influence in the

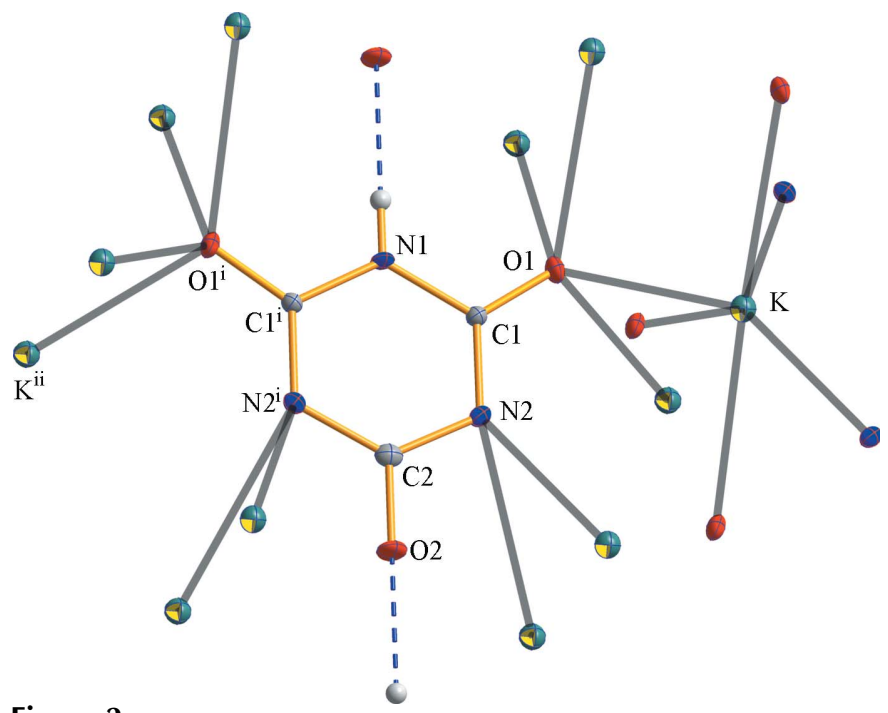

Figure 2

The structure of (2). Displacement ellipsoids are drawn at the $50 \%$ probability level, and the unique hydrogen bond is marked by a dashed line. [Symmetry codes: (i) $-x, y,-z+\frac{1}{2}$; (ii) $-x,-y+1, z-\frac{1}{2}$.

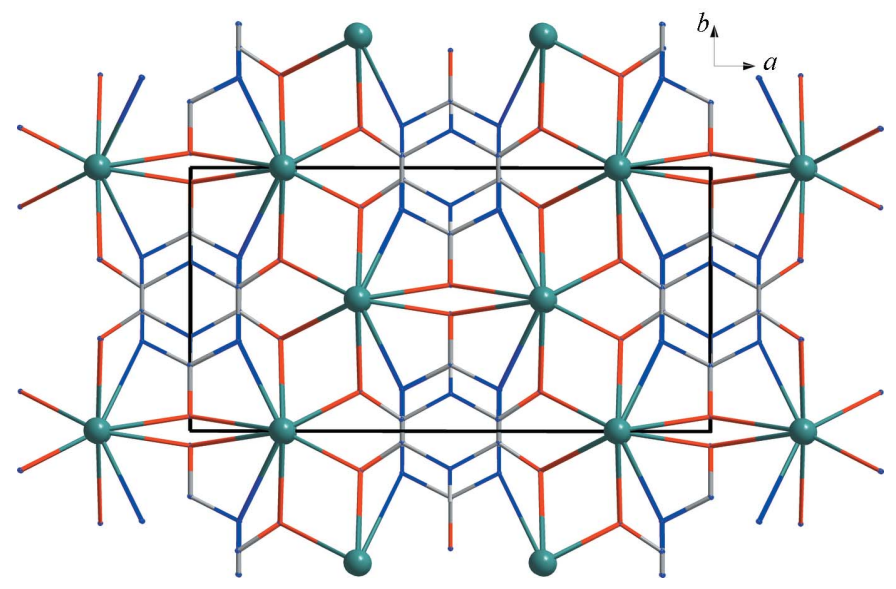

Figure 3

The crystal packing of (2), projected along the $c$ axis. 
crystal packing. The lone hydrogen bond runs parallel to the $b$ axis but is omitted from Fig. 3.

\subsection{Compounds (3) and (4)}

Our experiments with the reaction stoichiometry thus far yielded two different chemical compounds. We experimented with this ratio further by using 0.5 equivalents of $\mathrm{K}_{2} \mathrm{CO}_{3}$ with 1 equivalent of $\mathrm{CYH}_{3}$ to give a $\mathrm{K}: \mathrm{CYH}_{3}$ ratio of 1:1. This change in reaction stoichiometry yielded a third complex, compound (3), this time with coordinated water. To be sure that this was not a one-off observation the reaction was repeated many times at both $1: 1$ and $2: 1 \mathrm{~K}: \mathrm{CYH}_{3}$ with the same two results being achieved each time.

Compound (4), the rubidium analogue of (3), was also prepared. Unlike potassium, rubidium showed no change in the structure of the product as a result of varying the stoichoimetries and the same product resulted after many experiments with different reaction stoichoiometries. Compound (4) is isostructural with compound (3) but the crystals grown were not large enough for neutron diffraction, so only the X-ray structure was determined. Thus, the following discussion relates to (3) but the conclusions are equally applicable to (4). Table 1 contains a summary of the experimental parameters for (4).

The crystal structure of (3) as determined by X-ray diffraction is presented in Fig. 4. [The structure and subsequent discussions hereafter relate to a deuterated sample which was prepared especially for neutron diffraction and investigated also by X-ray diffraction to confirm that deuteration did not change the structure; although the initial discovery was made using data collected from a non-deuterated sample, it is the X-ray data pertaining to this deuterated structure which are reported.] The space group was determined as $C 2 / m$ and three potassium cations and four water molecules lie on a crystallographic mirror plane. The atoms of the two $\mathrm{CYH}_{2}^{-}$ligands all lie on general positions. It was quickly realized that the structure as determined did not make

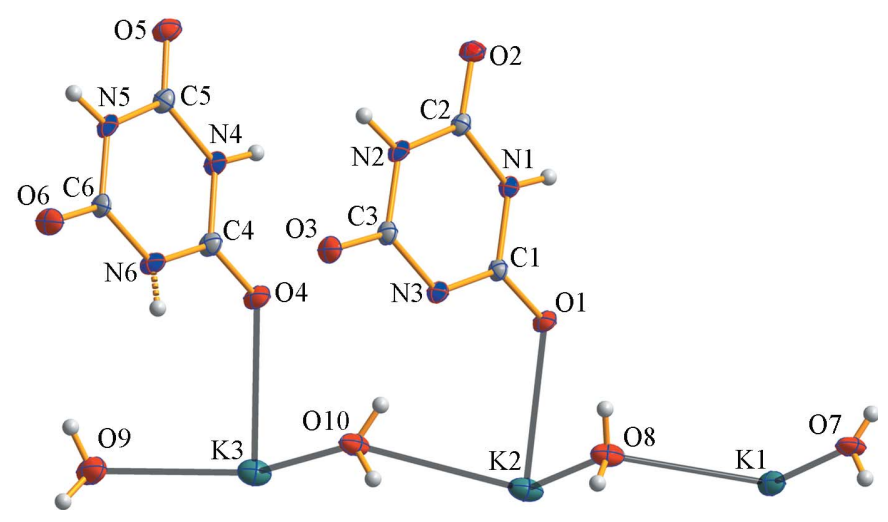

\section{Figure 4}

The apparent asymmetric unit of (3), as determined by X-ray diffraction. Displacement ellipsoids are drawn at the $50 \%$ probability level and the dashed line indicates a bond to a disordered D atom. chemical sense. If all the cations are lying on a mirror plane, then they each can be considered to have a charge of $0.5+$ in the asymmetric unit, giving an overall positive charge of $1.5+$. By contrast each anion is singly deprotonated and so gives a total negative charge of $2-$. Thus, the charges do not balance and there is $0.5+$ missing somewhere. The difference-Fourier map contained no large peaks indicating a fourth unassigned potassium ion, so attention focused on the only other atoms that could affect the charge of the compound, the $\mathrm{D}$ atoms.

A difference-Fourier map of the environment around atoms $\mathrm{N} 3$ and N6 was examined for any indication of a missed $\mathrm{H}$ atom. As can be seen in Fig. 5, the residual electron density surrounding atom $\mathrm{N} 3$ is insignificant and is no greater than the electron density found within the bonds of the cyanurate ring. On the other hand, the residual electron density around the N6 atom is much clearer and more concentrated, more so than that around N3 and more so than the residual bonding electron density of the ligand. This indicated that an $\mathrm{H}$ atom might be located here. However, whilst selection of this peak as an $\mathrm{H}$ atom and refinement of its coordinates may improve the refinement result, it does not solve the chemical problem with the charges. Placing an $\mathrm{H}$ atom here results in a charge imbalance with $0.5+$ in excess. In order to resolve this problem we tried two different approaches.

(1) Assume that the mirror plane is only a pseudo-symmetry element and remove it, assigning the structure to space group $C 2$. This assumption doubles the size of the asymmetric unit such that it contains three potassium centres (now in general positions), four cyanuric ligands and four water molecules, also in general positions. The strategy was then to examine difference Fourier maps for every cyanuric ligand to determine if one of the four definitely showed three strong $\mathrm{N}-\mathrm{D}$ deuterium peaks whilst the other three showed only two strong $\mathrm{N}-\mathrm{D}$ deuterium peaks.

This approach failed for two important reasons. Firstly, it was not overwhelmingly clear from any of the difference maps which ligand was $\mathrm{C}_{3} \mathrm{D}_{3} \mathrm{~N}_{3} \mathrm{O}_{3}$ and which were $\mathrm{C}_{3} \mathrm{D}_{2} \mathrm{~N}_{3} \mathrm{O}_{3}$. Secondly, the refinement of at least half the non-D atoms in the asymmetric unit was unstable, with many becoming 'nonpositive definite', indicating that the inversion centre should be present in the structural model to fit this set of data. Given the unconvincing Fourier analyses, and poor refinement of the anisotropic displacement parameters of several atoms that should be well defined, this model was rejected.

(2) Assume the mirror plane is a genuine symmetry element, requiring the additional 'missing' $\mathrm{H}$ atom to be disordered on either side of it, with an occupancy of $50 \%$ on each site. This approach makes chemical sense, as the charges balance properly and no restraints were needed on any of the anisotropic displacement parameters. The final $R 1$ value of 0.0335 implies that the problem had been resolved. However, this was not the case. Fig. 6 shows the result of applying the mirror plane on which the potassium cations and water molecules reside. Because of the mirror symmetry, water D atoms must be symmetry-equivalent and either both lie on the mirror plane or each lies on one side of it. The latter is apparently the case for all water molecules in this structure. 
However, as shown in Fig. 6, this brings D7 within a very close distance $(1.31 \AA)$ of the disordered D6N and its symmetry equivalent. No two D atoms can be brought this close in a correct structure; one would expect some sort of twisting of the water molecule to relieve the steric strain. However, such twisting would necessitate breaking the mirror symmetry and, as was noted above, a model in which the mirror symmetry is removed does not refine satisfactorily.

A more complicated model containing disordered water $\mathrm{H}$ atoms could also be constructed. Unfortunately, as the positions and occupancies of $\mathrm{H}$ atoms are unreliable when determined by X-ray diffraction, such a model would be unsuccessful.

In order to investigate further the behaviour of these D atoms we collected a full single-crystal neutron diffraction data set, with the aim of refining the occupancies of the $\mathrm{D}$
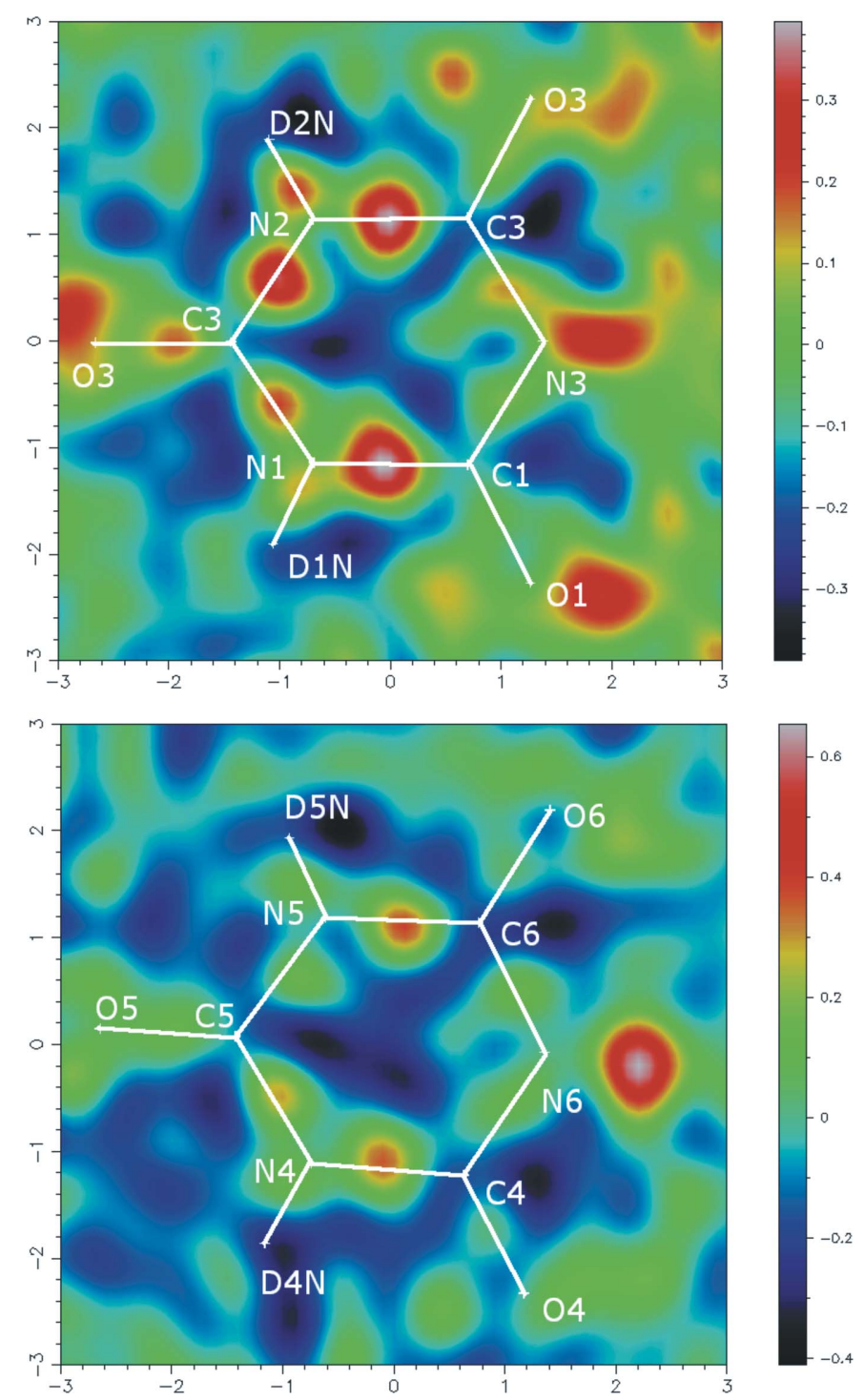

Figure 5

Difference-Fourier maps of both cyanurate rings in the X-ray-determined structure of (3), showing the residual electron density about N3 (top) and N6 (bottom). atoms. Several independent batches of deuterated complexes of (3) were prepared and taken to the ISIS neutron source for single-crystal neutron diffraction experiments. A crystal with a total volume of approximately $4 \mathrm{~mm}^{3}$ was selected and mounted. Initial tests showed good diffraction recorded on each detector, and even a relatively intense back-scattering was detected. To determine the unit cell, around 100 strong reflections were collected by each detector and the data were then indexed to automatically give a unit cell that matched that determined by X-ray analysis. When a sufficient amount of data had been collected to facilitate an attempt to refine the structure, a trial model was used based on the atomic coordinates from the X-ray structure. Starting without the D atoms, initial least-squares refinement was rather unsatisfactory, not particularly unusual since deuterium is the second strongest neutron scatter in this compound. As D atoms bonded to N1, N2, N4, N5 and all the water molecules, except for those on O7, were located in successive Fourier maps the refinement improved markedly to a respectable $R 1=0.1039$. There remained, however, a lot of residual diffraction density around the $\mathrm{O} 7$ atom, with two very large peaks about $0.96 \AA$ away from $\mathrm{O} 7$, subtending an angle of $113^{\circ}$ at $\mathrm{O} 7$. One of these peaks was located exactly on the mirror plane; the second was not. Selection of these peaks as D atoms, followed by anisotropic least-squares refinement, further improved the result to $R 1=0.0756$. This was, however, the best result that could be obtained with this unit cell and space group. The anisotropic displacement parameters of the $\mathrm{D}$ atoms attached to atom $\mathrm{O} 7$ remained rather unstable during further refinement cycles.

Aside from the steric crowding around this water molecule the charge balance problem still remained to be dealt with. Difference maps did show a relatively strong peak corresponding to a $\mathrm{D}$ atom bonded to N6. This peak was selected as deuterium and refined, with the site occupation factor for the atom freely refined. Rather than refining to give an occupancy of $\sim 0.5$ and a sensible displacement ellipsoid, the occupancy refined to $\sim 1$ with a rather large and elongated ellipsoid. Thus, simply using the trial model determined by X-ray analysis coupled with the data integrated so far did not as yet offer an acceptable explanation of the problem.

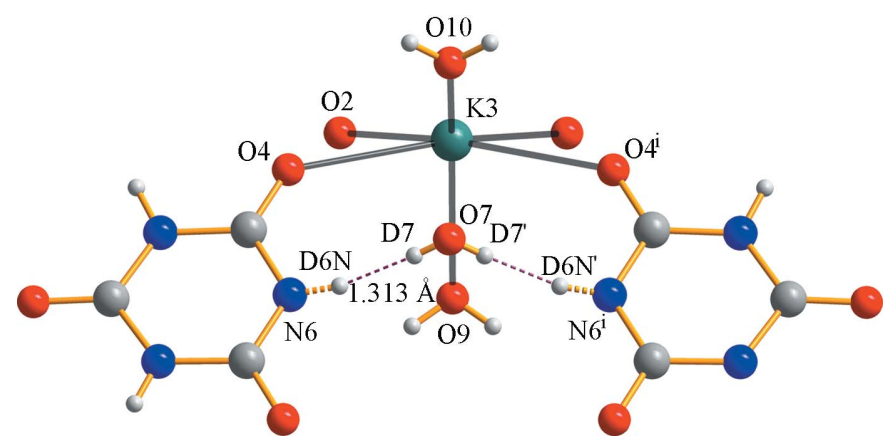

Figure 6

The result of applying the mirror symmetry element in the initial X-raydetermined structure of (3). The unacceptable steric interaction between atoms D6N and D7 is represented by a dashed line. 
As data collection proceeded further it was noticed that there were many rather weak unindexed reflections with halfinteger values of $l$. These suggest a supercell, corresponding to the unit cell with the $c$ axis doubled in length. The data were thus reindexed on this supercell, and re-integrated. Examination of the new reflection data suggested that the space group could be either $I a$ or I2/a. Trial models without D atoms were created in both space groups then refined using this second set of neutron data. Refinement in $I a$ was very poor; however, refinement in $I 2 / a$ was rather more satisfactory and, with the addition of $\mathrm{D}$ atoms, quickly converged. Leastsquares restraints were used on some of the $\mathrm{C}$ and $\mathrm{O}$ atoms to control their anisotropic displacement parameters. The model now contained three potassium cations, four water molecules and four cyanuric ligands. Each cyanuric ligand was examined in turn using observed and difference-Fourier maps to identify which one was in fact neutral. As shown in Fig. 7, the ligand containing N4, N5 and N6 showed three distinct peaks corresponding to deuterium in the observed Fourier map, identifying this ligand as $\mathrm{CYD}_{3}$. The remaining three ligands showed no significant unaccounted diffraction density in either observed or difference maps, so we were confident that we had located the $\mathrm{CYD}_{3}$ ligand as distinct from the remaining three $\mathrm{CYD}_{2}^{-}$ligands, and the charges now balanced, as the chemical formula is $\left[\mathrm{K}_{3}\left(\mathrm{CYD}_{2}\right)_{3}\left(\mathrm{CYD}_{3}\right)\left(\mathrm{D}_{2} \mathrm{O}\right)_{4}\right]$.

With the charge balance problem solved our attention then turned to the question of the unfavourable steric interactions between the $\mathrm{D}$ atoms of one water molecule and the $\mathrm{CYD}_{3}$ ligand. As noted above the first model (in $C 2 / m$ ) used in the analysis of the neutron diffraction data showed that one of the water molecules did not obey the mirror symmetry of that space group, instead placing one D atom exactly on the crystallographic mirror plane. In this new model all atoms lie in general positions and the relative orientation of all water $\mathrm{D}$ atoms is the same as in the first model, with three water

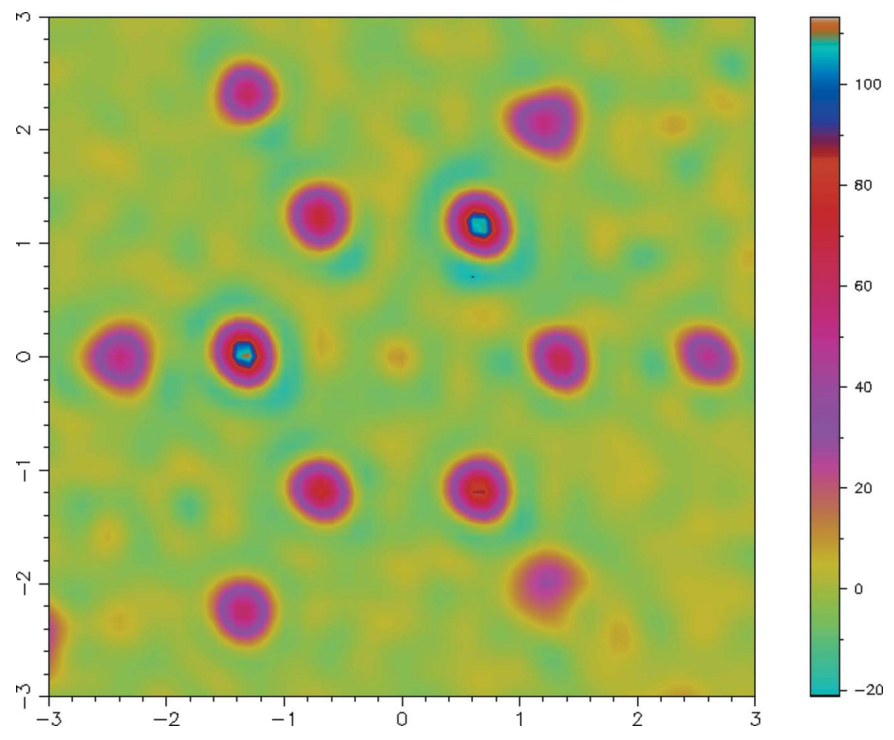

Figure 7

An $F_{\text {obs }}$ Fourier map of the $\mathrm{CYD}_{3}$ ligand as determined by neutron diffraction with the second model. The locations of all 12 atoms in the molecule are clear. molecules obeying pseudo-mirror symmetry and one molecule breaking it. As Fig. 8 shows, the presence of D5 causes D16A and $\mathrm{D} 16 B$ to twist away, allowing an $\mathrm{N}-\mathrm{D} \cdots \mathrm{O}$ interaction to form, and breaking the pseudo-symmetry. The $\mathrm{D}$ atoms attached to atom $\mathrm{O} 15$ suffer no such steric hindrance from their deprotonated $\mathrm{CYD}_{2}{ }^{-}$neighbours and thus can form two pseudo-symmetrical $\mathrm{O}-\mathrm{D} \cdots \mathrm{N}$ interactions.

To summarize: the crystallographic mirror symmetry determined by X-ray diffraction is actually false, broken by the presence of D5 within the structure, which, to minimize steric hindrance and maximize hydrogen-bonding interactions, causes a twist of the water molecule O16, which in turn breaks the mirror symmetry observed by the remaining water molecules. Atom D5 also causes atoms N2 and N5 to be symmetryinequivalent and these thus also break the mirror pseudosymmetry. This breaking of the symmetry results in the formation of a supercell, caused only by the difference in $\mathrm{D}$-atom positions. It is thus no surprise that this supercell was not detected at all by X-ray diffraction, given the poor scattering of X-rays by the electron density associated with $\mathrm{D}$ atoms. This supercell turned out to be the true unit cell. The correct structure of (3), as determined by neutron diffraction, is shown in Fig. 9. The structures of (3) and (4) determined by $\mathrm{X}$-ray diffraction are not completely correct, as they have been determined in a sub-cell with the incorrect space group as a consequence of the very weak scattering of X-rays by $\mathrm{H}$ or $\mathrm{D}$ atoms. Although the results are shown here for comparison with the true structure determined with neutrons, and the CIFs are available as supplementary material, these have not been deposited in the Cambridge Structural Database since it is considered inappropriate to include in the database structures that are known to be strictly incorrect.

The asymmetric unit contains three crystallographically independent potassium cations, three $\mathrm{CYD}_{2}{ }^{-}$anions, one neutral $\mathrm{CYD}_{3}$ molecule and four water molecules, all on general positions. The coordination environments of all three metal centres are shown in Fig. 10. Atoms K1 and K3 are both eight-coordinate but their coordination geometries are rather different, with $\mathrm{K} 1$ having a typical square-antiprismatic coor-

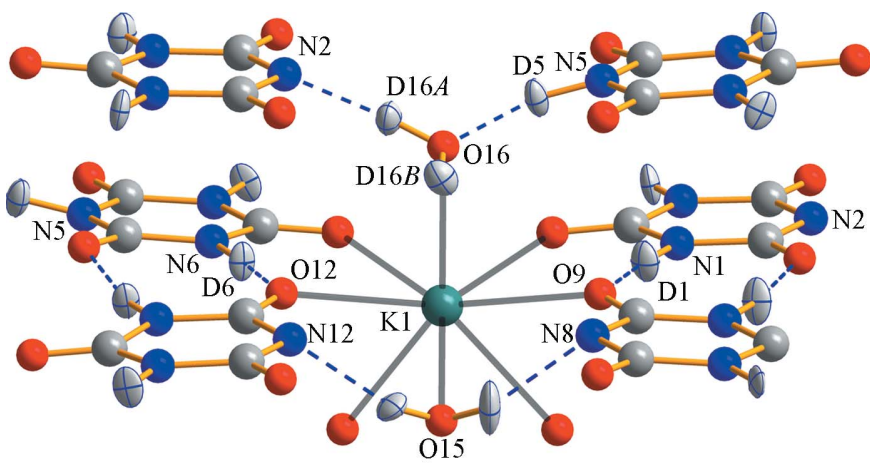

Figure 8

Part of the correct structure of (3) determined by neutron diffraction. The pseudo-mirror symmetry of the structure is approximately observed by all atoms except D5 and D16B. Their positions break the symmetry and result in extra weak reflections in the diffraction pattern which were not identified by X-ray diffraction. 
dination environment whilst $\mathrm{K} 3$ has a square-antiprismatic environment that is rather more distorted, as if one side of the antiprism has been flattened out, such that the O14-K3$\mathrm{O} 13$ angle is approximately $143^{\circ}$ and the $\mathrm{O} 3-\mathrm{K} 3-\mathrm{O} 5$ angle is approximately $121^{\circ}$; ideally these would be $90^{\circ}$ for undistorted geometry. The environment of seven-coordinate $\mathrm{K} 2$ is rather more difficult to describe quantitatively, as it does not have a typical seven-coordinate geometry. Five of the coordinating $\mathrm{O}$ atoms form an approximate pentagon, to which addition of an apical coordinated $\mathrm{O}$ atom generates a pentagonal-based pyramid. The seventh $\mathrm{O}$ atom, rather than occupying the second axial site (which would give a regular pentagonalbased bipyramid), is distorted well away from this ideal position to bridge atoms $\mathrm{K} 2$ and $\mathrm{K} 3$ (this is the bridging water molecule in Fig. 10). It is worthy of note that, unlike compounds (1) and (2), there is no $\mathrm{K}-\mathrm{N}$ coordination in this structure; with four water molecules in the structure the $\mathrm{N}$ atoms are used as hydrogen-bonding acceptors and so cannot coordinate to the metal. The crystal packing of (3) is rather

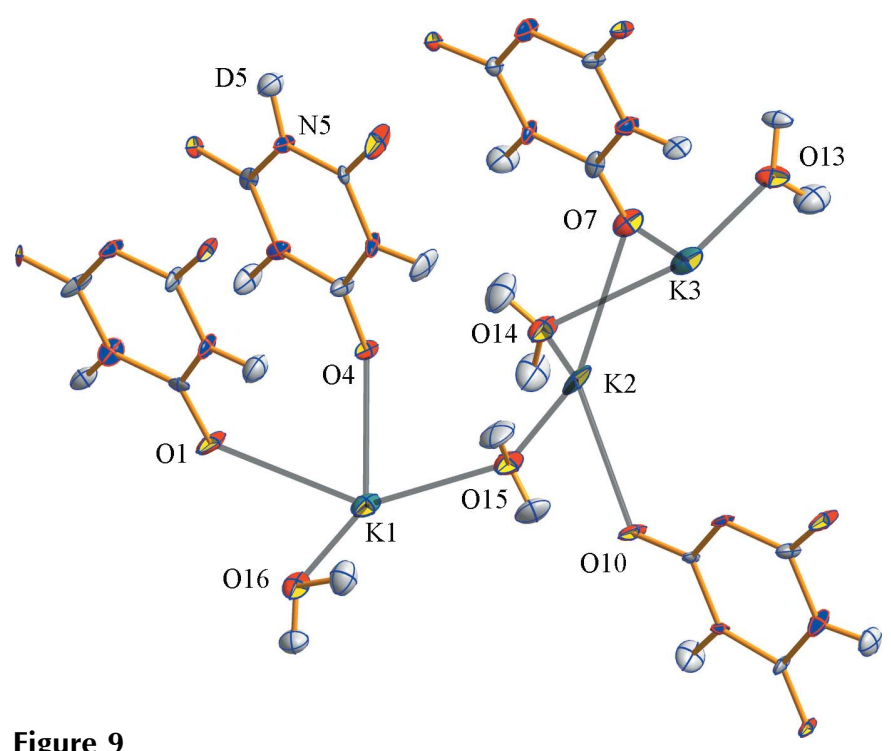

Figure 9

The asymmetric unit of (3) as correctly determined by neutron diffraction. Displacement ellipsoids are drawn at the $50 \%$ probability level; atom labelling has been restricted for clarity.

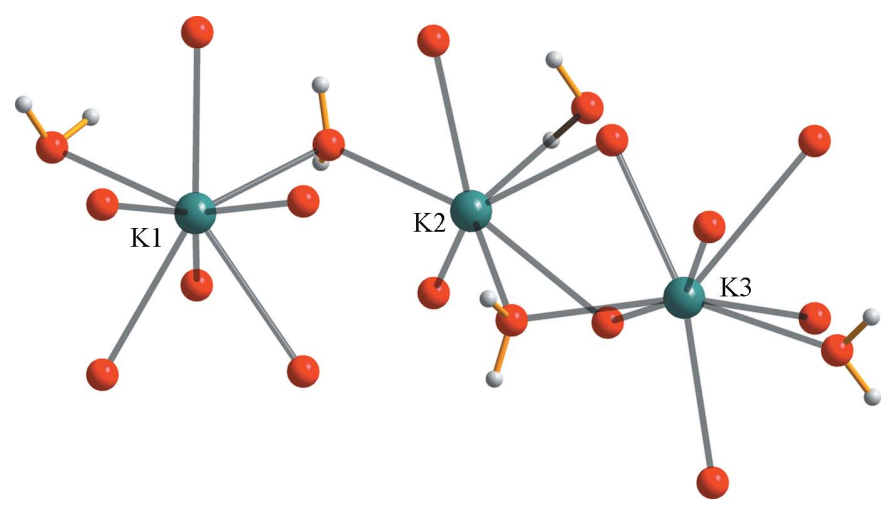

Figure 10

The coordination environments of the three independent potassium centres in the neutron-determined structure of (3). unexceptional for a cyanurate complex. Polymeric water coordination to the potassium centres forms a thin twodimensional sheet; tapes of $R_{2}^{2}(8)$ hydrogen-bonded $\mathrm{CYD}_{2}$ and $\mathrm{CYD}_{3}$ ligands are linked to this sheet via coordination and hydrogen bonding to form an overall three-dimensional structure. Such crystal packing is very common in cyanurate complexes.

\section{Conclusion}

The potassium-cyanuric acid reaction in aqueous solution was found to be particularly sensitive to stoichiometry, with three different complexes formed depending on the relative amount and type of base used. Using equimolar amounts of $\mathrm{CYH}_{3}$ and $\mathrm{K}_{2} \mathrm{CO}_{3}$ (and so an effective $\mathrm{K}: \mathrm{CYH}_{3}$ ratio of 2:1) always resulted in the product $\left[\mathrm{K}^{+}\left(\mathrm{CYH}_{2}{ }^{-}\right)\left(\mathrm{H}_{2} \mathrm{O}\right)\right]$, (1), which was first reported some 15 years ago. By using a large excess of $\mathrm{KOH}$ we synthesized a new compound, $\left[\mathrm{K}_{2}^{+}\left(\mathrm{CYH}^{2-}\right)\right]$, (2). This compact dense structure features doubly deprotonated cyanuric acid and, surprisingly, no water is present. A direct result of the double deprotonation is the loss of the $R_{2}^{2}(8)$ hydrogen-bonding motif, which is almost always found in cyanuric structural chemistry. The most interesting compound formed, however, was (3). Single-crystal X-ray diffraction gave a result which, although crystallographically largely sound, did not make chemical sense as a result of a charge imbalance between three cations and two anions and, in an attempt to rectify this by inclusion of a disordered $\mathrm{H}$ atom, an impossibly short contact between two H-atom sites. Resolution of these issues was achieved through a single-crystal neutron diffraction study carried out on a deuterated sample of this compound, leading to a supercell model with all atoms in general positions, the assignment of one neutral and three deprotonated organic ligands, and an ordered arrangement of $\mathrm{D}$ atoms with sensible interactions; the true structure has only pseudo-mirror symmetry, which is significantly broken by only two D atoms, an effect essentially invisible to X-ray diffraction.

We thank the EPSRC for funding and the CCLRC for the allocation of neutron beam-time at ISIS.

\section{References}

Allen, F. H. (2002). Acta Cryst. B58, 380-388.

Aoki, S., Shiro, M., Koike, T. \& Kimura, E. (2000). J. Am. Chem. Soc. 122, 576-584.

Arduini, M., Crego-Calama, M., Timmerman, P. \& Reinhoudt, D. N. (2003). J. Org. Chem. 68, 1097-1106.

Barford, E. D., Jeffrey, D. J., Marshall, J. \& Raynor, P. A. (1989). Lavatory Cleansing Blocks Containing Chlorinated Cyanuric Acid Derivatives and Metal Salts. UK Patent 2217343.

Berl, V., Schmutz, M., Krische, M. J., Khoury, R. G. \& Lehn, J.-M. (2002). Chem. Eur. J. 8, 1227-1244.

Bernstein, J., Davis, R. E., Shimoni, L. \& Chang, N.-L. (1995). Angew. Chem. Int. Ed. Engl. 34, 1555-1573.

Blount, D. H. (2000). Flame Retardant Compositions Utilizing a Mixture of Cyanuric Acid and Cyamelide Compounds. US Patent 6 423250. 
Brandenburg, K. \& Putz, H. (2004). DIAMOND3. University of Bonn, Germany.

Bruker (2001). SAINT and SMART. Bruker AXS Inc., Madison, Wisconsin, USA.

Brunner, H., Hollman, A., Nuber, B. \& Zabel, M. (2001). J. Organomet. Chem. 633, 1-6.

Duisenberg, A. J. M., Kroon-Batenburg, L. M. J. \& Schreurs, A. M. M. (2003). J. Appl. Cryst. 36, 220-229.

Falvello, L. R., Hitchman, M. A., Palacio, F., Pascual, I., Schultz, A. J., Stratemeier, H., Tomas, M., Urriolabeitia, E. P. \& Young, D. M. (1999). J. Am. Chem. Soc. 121, 2808-2819.

Falvello, L. R., Pascual, I. \& Tomas, M. (1995). Inorg. Chim. Acta, 229, 135-142.

Falvello, L. R., Pascual, I., Tomas, M. \& Urrioldbeitia, E. P. (1997). J. Am. Chem. Soc. 119, 11894-11902.

Farrugia, L. J. (1999). J. Appl. Cryst. 32, 837-838.

Felix, O., Crego-Calama, M., Lutyen, I., Timmerman, P. \& Reinhoudt, D. N. (2003). Eur. J. Org. Chem. pp. 1463-1474.

Gutmann, M. J. \& Wilson, C. C. (2001). SXD-2001. ISIS, Rutherford Appleton Laboratories, Oxfordshire, England.

Hudec, J., Macho, V. \& Hudec, J. (1987). Cyanuric Acid as a Plant Growth Regulator. Czech Patent 240375.

Keen, D. A., Gutmann, M. J. \& Wilson, C. C. (2006). J. Appl. Cryst. 39, 714-722.

Marsh, R. E., Kapon, M., Hu, S. \& Herbstein, F. H. (2002). Acta Cryst. B58, 62-77.

Mascal, M., Hansen, J., Fallon, P. S., Blake, A. J., Heywood, B. R., Moore, M. H. \& Turkenburg, J. P. (1999). Chem. Eur. J. 5, 381-384.

Munakata, M., Wen, M., Suenaga, Y., Kuroda-Sowa, T., Maekawa, M. \& Anahata, M. (2001a). Polyhedron, 20, 2037-2043.
Munakata, M., Wen, M., Suenaga, Y., Kuroda-Sowa, T., Maekawa, M. \& Anahata, M. (2001b). Polyhedron, 20, 2321-2327.

Nichol, G. S. \& Clegg, W. (2006a). Inorg. Chim. Acta. 359, 34743480.

Nichol, G. S. \& Clegg, W. (2006b). Polyhedron, 25, 1043-1056.

Nonius (1999). COLLECT. Nonius BV, Delft, The Netherlands.

Rao, C. N. R., Ranganathan, A., Pedireddi, V. R. \& Raju, A. R. (2000). Chem. Commun. pp. 39-40.

Server-Carrio, J., Escriva, E. \& Folgado, J.-V. (1998). Polyhedron, 17, $1495-1501$.

Seto, C. T., Mathias, J. P. \& Whitesides, G. M. (1993). J. Am. Chem. Soc. 115, 1321-1329.

Seto, C. T. \& Whitesides, G. M. (1993). J. Am. Chem. Soc. 115, 13301340.

Sheldrick, G. M. (2001). SHELXTL. Version 6. Bruker AXS Inc., Madison, Wisconsin, USA.

Sheldrick, G. M. (2003). SADABS. University of Göttingen, Germany.

Siebers, D. L. \& Caton, J. A. (1990). Combust. Flame, 79, 3146.

Slade, P. G., Raupach, M. \& Radoslovich, E. W. (1973). Acta Cryst. B29, 279-286.

Sysoeva, T. F., Branzburg, M. Z., Gurevich, M. Z. \& Starikova, Z. A. (1990). Russ. J. Struct. Chem. 31, 90-94.

Whitesides, G. M., Simanek, E. E., Mathias, J. P., Seto, C. T., Chin, D. N., Mammen, M. \& Gordon, D. M. (1995). Acc. Chem. Res. 28, 37-44.

Wilson, C. C. (2005). Z. Kristallogr. 220, 385-398.

Zerkowski, J. A., MacDonald, J. C., Seto, C. T., Wierda, D. A. \& Whitesides, G. M. (1994). J. Am. Chem. Soc. 116, 2382-2391. 